\title{
VALOR NUTRICIONAL DA PLANTA, PADRÕES DE FERMENTAÇÃO E QUALIDADE DA SILAGEM DE TRITICALE EM SEIS IDADES DE CORTE
}

\author{
Nutritional value of the forage, fermentation patterns and silage quality of \\ triticale ( $X$ Triticosecale Wittimack) at six cutting ages \\ Jackson Silva e Oliveira ${ }^{1}$, Éder Cristian Malta de Lanes ${ }^{2}$, Fernando César Ferraz Lopes ${ }^{3}$, \\ Emerson José Dornelas de Almeida ${ }^{4}$, Sarita Gonçalves do Carmo ${ }^{4}$
}

\begin{abstract}
Resumo
Embora tenha potencial de adaptabilidade para várias regiões do Brasil, o triticale, gramínea produtora de grãos e forragem, tem sido mais utilizado na Região Sul do Brasil. Neste trabalho, objetivou-se conhecer o valor nutritivo da planta de triticale e algumas características de sua silagem quando cultivada na Região Sudeste e submetida a seis idades de corte. O experimento foi instalado (07/ 07/95) em uma propriedade particular no município de Guarani (MG), em delineamento inteiramente casualizado, com quatro repetições, sendo avaliado o efeito da idade de corte $(73,80,87,94,101$ e 108 dias) sobre o valor nutricional da forragem do triticale e sobre os padrões de fermentação e de qualidade da sua silagem. Houve incremento de 0,46 e decréscimo de 0,09 unidades porcentuais, respectivamente, nos teores de matéria seca (MS) e de proteína bruta (PB) da silagem, para cada dia adicional na idade de corte, sendo os maiores teores de MS obtidos de plantas cortadas aos 87 e 101 dias. Foi observado comportamento quadrático entre os valores $(\mathrm{P}<0,05)$ de $\mathrm{pH}$ das silagens e a idade de corte do triticale, onde os valores de $\mathrm{pH}$ variaram entre 3,7 e 5,5. As menores concentrações de ácido acético, entre 1,93 e 3,60\% da MS, foram observadas de 87 a 101 dias de crescimento das plantas. Na silagem produzida a partir das plantas cortadas aos 73 dias de idade, foi observada concentração de ácido lático de $0,97 \%$ da MS. A maior $(\mathrm{P}<0,05)$ concentração de ácido lático foi observada na silagem produzida a partir das plantas cortadas aos 94 dias de crescimento (12,05\% da MS). Os parâmetros de degradação ruminal in situ da MS da forragem verde variaram de 74,6 a 89,5\% (degradabilidade potencial), de 2,8 a $3,8 \% / \mathrm{h}$ (taxa de degradação), e de 42,0 a $51,0 \%$ (degradabilidade efetiva, sob taxa de passagem ruminal de $5 \% / \mathrm{h}$ ). As silagens obtidas de plantas cortadas aos 87, 94 e 101 dias de crescimento apresentaram melhor qualidade nutricional.
\end{abstract}

Termos de indexação: Composição química, degradabilidade ruminal, estádio de crescimento, forragem, parâmetro de fermentação, ruminante, triticosecale.

\begin{abstract}
Although with potential to adapt in many regions of Brazil, the triticale, a grass that produces grain and forage, has been used only in the South of the country. The objective of this work was to study the nutritive value of the triticale forage as well as the fermentation parameters and quality of its silage when it is grown in Southeast Region and cut at six different ages. The experiment was carried (07/07/95) out at Guarani (Minas Gerais State, Brazil). Cutting ages studied were 73, 80, 87, 94, 101 and 108 days after sowing, using a casual design with four replications. There was an increase of 0.46 and a decrease of 0.09 percent units on dry matter (DM) and crude protein $(\mathrm{CP})$ percentages, respectively, for each additional day in the cutting age. The highest values of DM were those obtained by plants cut between 87 and 101 days. Quadratic relationship was observed between silage $\mathrm{pH}$ values and cutting ages, where $\mathrm{pH}$ values varied between 3.7 and 5.5, and the lowest acetic acid concentrations, between 1,93 and 3,60\% of the DM. Silage from plants cut after 73 days of age presented $0,97 \%$ of lactic acid in the DM. The highest $(\mathrm{P}<0,05)$ concentration of lactic acid was observed in silage produced from the plants cut at 94 growth days $(12.05 \%$ of the $\mathrm{DM})$. The in situ ruminal degradation parameters of fresh forage ranged from 74.6 to $89.5 \%$ (potential degradability), from 2.8 to $3.8 \% / \mathrm{h}$ (degradation rate), and from 42.0 to $51.0 \%$ (effective degradability under $5 \% / \mathrm{h}$ of passage rate). Silage obtained from plants cut at 87, 94 and 101 growth days presented better nutritional quality.
\end{abstract}

Index terms: Chemical composition, ruminal degradability, growing stage, roughage, ensiling characteristics, ruminant, triticosecale.

(Recebido em 21 de outubro de 2008 e aprovado em 16 de setembro de 2009)

\section{INTRODUÇÃo}

Apesar da grande produção de biomassa das gramíneas tropicais, a estacionalidade de sua produção representa problema no período seco do ano. A utilização de gramíneas de clima temperado como alternativa para amenizar a sazonalidade da produção de forragem tem sido bastante estudada (Veasey et al., 1977; Ferolla et al., 2007; Ruiz et al., 2007; Moreira et al., 2007).

Dentre as forrageiras de inverno o triticale $(X$ Triticosecale Wittmack), gramínea obtida do cruzamento

'EMBRAPA Gado de Leite - Eugênio do Nascimento - 610 - 36038-330 - Juiz de Fora, MG - jackoliv@cnpgl.embrapa.br ${ }^{2}$ Centro de Ensino Superior de Juiz de Fora/CES/JF - Juiz de Fora, MG

${ }^{3}$ EMBRAPA Gado de Leite - Juiz de Fora, MG

${ }^{4}$ Universidade Federal de Juiz de Fora/UFJF - Juiz de Fora, MG 
entre espécies de trigo (Triticum spp.) e de centeio (Secale spp.) (Zamotto et al., 2009) tem demonstrado resultados promissores na produção de grãos e de forragem, destacando-se pela rusticidade e produtividade (Baier, 1989; Bortolini et al., 2004), e pelo grande potencial de adaptabilidade para as condições brasileiras (Baier \& Nedel, 1985). Além disso, apresenta boas características agronômicas, resistência a doenças e pragas comuns aos cereais (Carvalho et al., 1980), adapta-se bem a solos arenosos, de boa drenagem, $\mathrm{pH}$ baixo e com presença de alumínio trocável (Perez Gomar \& Bemahaja, 1992).

Para que o triticale seja eficientemente utilizado sob a forma de silagem de planta inteira na alimentação de ruminantes, parâmetros indicativos do processo de fermentação e da qualidade da massa ensilada devem ser avaliados, principalmente, com relação à idade das plantas no momento do corte para ensilagem (Jobim et al., 1996; Jayme et al., 2009).

Dessa forma, conduziu-se este trabalho, com objetivo de avaliar o efeito da idade de corte do triticale sobre o valor nutricional da forragem verde e sobre os padrões de fermentação e de qualidade de sua silagem, em condição de cultivo de inverno irrigado, na Zona da Mata de Minas Gerais.

\section{MATERIAL E MÉTODOS}

O experimento foi realizado em área plana de solo homogêneo, em propriedade particular, localizada no município de Guarani, sob altitude de $420 \mathrm{~m}$, latitude de $21^{\circ} 21^{\prime} \mathrm{S}$ e longitude $43^{\circ} 03^{\prime} \mathrm{W}$, situado na Zona da Mata de Minas Gerais, região de clima CwA, segundo classificação de Köppen.

Asemeadura foi feita em 07/07/1995, utilizando 100 sementes viáveis da cultivar BR-4 por metro de linha, espaçadas em $25 \mathrm{~cm}$. Na semeadura foram utilizados 500 $\mathrm{kg} /$ ha da fórmula 4-14-8 e na adubação de cobertura, realizada em 09/08/95, 425 e $75 \mathrm{~kg} /$ ha de sulfato de amônio e cloreto de potássio, respectivamente. A cultura foi irrigada por aspersão, mantendo o solo próximo da capacidade de campo. A parcela experimental era formada por oito linhas de $4 \mathrm{~m}$, sendo o espaçamento entre parcelas de $50 \mathrm{~cm}$

Foram avaliadas seis idades de corte para ensilagem do triticale (73, 80, 87, 94, 101 e 108 dias de crescimento), utilizando delineamento experimental inteiramente casualizado, com quatro repetições.

As plantas foram cortadas, manualmente, pela manhã, sob altura aproximada de $5 \mathrm{~cm}$ do nível do solo, sendo, posteriormente, desintegradas em picadeira estacionária situada próximo ao local de cultivo do triticale. Uma amostra de cada parcela foi ensilada em silos experimentais de PVC (40 x $10 \mathrm{~cm}$ de diâmetro), dotados de válvula tipo bunsen. Imediatamente antes da ensilagem foram retiradas amostras da forragem picada, visando às determinações de matéria seca (MS), de proteína bruta (PB) e de fibras em detergente neutro (FDN) e ácido (FDA), segundo procedimentos relatados em Silva \& Queiroz (2002).

Para a estimativa da digestibilidade ruminal in situ da MS da forragem verde, foram utilizadas amostras de apenas três repetições para cada idade de corte. Foi adotado o procedimento sugerido por Tomich \& Sampaio (2004), em que apenas um animal é utilizado para incubação ruminal. As amostras de forragem verde foram pré-secadas em estufa de ventilação forçada $\left(72 \mathrm{~h}, 65^{\circ} \mathrm{C}\right)$, moídas em moinho de facas, dotado de peneira com abertura de malhas de $5 \mathrm{~mm}$, acondicionadas em sacos de náilon $(10 \times 20 \mathrm{~cm}$; porosidade de 50 ì; 10 a $20 \mathrm{mg}$ de amostra por $\mathrm{cm}^{2}$ de área de saco) e incubadas por 6, 24, 48 e 96 h no rúmen de uma vaca Holandês x Zebu, não-lactante, recebendo silagem de milho ad libitum.

Os silos permaneceram fechados aproximadamente 150 dias. Após a abertura, a silagem presente nos primeiros $5 \mathrm{~cm}$ da parte superior foi descartada, sendo o restante homogeneizado e amostrado, visando à determinação do $\mathrm{pH}$ e às análises das concentrações dos ácidos orgânicos acético, propiônico, butírico e láctico, e de nitrogênio amoniacal como porcentagem do $\mathrm{N}$ total $\left(\mathrm{NH}_{3} / \mathrm{NT}\right)$, conforme metodologias descritas em Silva \& Queiroz (2002).

Para a determinação dos teores de MS, PB, FDN e FDA (Silva \& Queiroz, 2002), amostras de silagem foram pré-secadas por $72 \mathrm{~h}$ em estufa de ventilação forçada, regulada para $65^{\circ} \mathrm{C}$, e moídas em moinho de facas dotado de peneiras com crivos de $1 \mathrm{~mm}$.

Foi utilizado o procedimento PROC GLM do SAS Institute (1985) para a realização da análise de variância dos dados, e o teste SNK ao nível de 5\% de probabilidade para comparação das médias. Também foram realizadas regressões (PROC REG), visando a estudar o efeito da idade de corte do triticale sobre as composições químicas das forragens picadas e dos ensilados finais, bem como sobre os parâmetros de fermentação das silagens.

\section{RESULTADOS E DISCUSSÃO}

Os dados referentes à composição química da forragem verde picada do triticale em função da idade de corte estão apresentados na Tabela 1. Foi observado incremento $(\mathrm{P}<0,0001)$ de 0,63 unidades percentuais no teor de MS da forragem para cada dia adicional na idade de corte $(\mathrm{X})$ do triticale $\left(\mathrm{MS} \%=-31,923789+0,628684 \mathrm{X} ; \mathrm{r}^{2}=\right.$ $0,82)$. O maior valor de $\mathrm{MS}$ da forragem verde $(\mathrm{P}<0,05)$ foi 
obtido na planta com 108 dias de crescimento $(38,1 \%)$, seguido pelos cortes aos 101, 87 e 94 dias, enquanto que de 73 a 80 dias foram observados os menores teores de MS (Tabela 1). Avaliando o efeito do estádio de desenvolvimento das plantas (89 a 122 dias pós-semeadura) de três cultivares de triticale no período de inverno (Jaboticabal, SP), Jobim et al. (1996) também observaram que houve incremento $(\mathrm{P}<0,05)$ na concentração de MS da forragem com o avanço da maturidade da planta.

$\mathrm{O}$ teor de $\mathrm{PB}$ da forragem verde mostrou comportamento quadrático $(\mathrm{P}<0,05)$ com a idade de corte $\left(\mathrm{PB} \%=69,201037-1,046306 \mathrm{X}+0,004626 \mathrm{X}^{2} ; \mathrm{R}^{2}=0,84\right)$, sendo os valores extremos obtidos aos 73 e 108 dias de crescimento $(\mathrm{P}<0,05)$, respectivamente, de 17,9 e $9,7 \%$ de PB (Tabela 1). Em trabalho conduzido nos EUA com a cultivarTrical 96, Collar et al. (2004) também relataram decréscimo na concentração de PB, com o avanço no estádio de maturação da cultura. Em outro estudo com triticale, realizado no município de Rio Pomba (MG), Lopes et al. (2008) observaram decréscimo de PB da forragem verde com o avanço da maturidade, sendo os valores extremos obtidos aos 83 e 118 dias de crescimento, respectivamente, 17,9 e $11,6 \%$ de $\mathrm{PB}$.

Não foi observada diferença $(P>0,05)$ nas concentrações de FDN da planta inteira de triticale em função da idade de corte, sendo o valor médio observado de 76,95\%. Quanto à concentração de FDA na forragem verde, foi observado comportamento quadrático $(\mathrm{P}<0,05)$ com a idade de corte do triticale (FDA $\%=-82,442771+$ $\left.2,826969 \mathrm{X}-0,015845 \mathrm{X}^{2} ; \mathrm{R}^{2}=0,30\right)$, sendo o maior e o menor valor $(\mathrm{P}>0,05)$ obtidos aos 87 e 73 dias de crescimento, respectivamente, de 44,9 e 38,8\% de FDA (Tab. 1). Os teores de FDN, não estão de acordo com aqueles observados por Collar et al. (2004), Jobim et al. (1999) e Lopes et al. (2008), que relataram comportamento quadrático em seus experimentos. Para as concentrações de FDA, estas indicam o mesmo comportamento quando comparadas com outros estudos. Lopes et al. (2008) também observaram incremento, aproximadamente, aos 97 dias após a semeadura. Depois dessa idade de crescimento, os autores relataram decréscimo nos teores de FDA na forragem de triticale. Trabalhando com o cultivar "Trical 96", Collar et al. (2004), relataram que, até, aproximadamente, os 115 dias pós-semeadura, houve incremento nas concentrações de FDN e FDA. Depois dessa idade de crescimento, houve decréscimos nos teores destas frações fibrosas. Em um segundo experimento de seu trabalho, Collar et al. (2004) observaram incremento nas concentrações de FDN e FDA até a fase de florescimento da cultura, seguido de decréscimo até a fase de grãos farináceos macios. Em estudo conduzido no Brasil, Jobim et al. (1999) também relataram que até a fase de florescimento da cultura houve incremento e, a partir daí, foi observado decréscimo na concentração de FDN da forragem de seis genótipos de triticale.

As concentrações de PB estão de acordo com aquelas publicadas na literatura. No entanto, os valores observados para as concentrações de FDN, entre as idades de corte de 80 a 108 dias, e de FDA, entre as idades de corte de 80 a 94 dias, da forragem verde, podem ser considerados elevados em relação aos relatados na literatura. Ao avaliar o efeito do estádio de desenvolvimento das plantas (89 a 122 dias pós-semeadura) de três cultivares de triticale no período de inverno, em Jaboticabal (SP), Jobim et al. (1996) relataram valores de FDN e FDA (\% da MS) variando, respectivamente, de 55,1 a 64,8\% e de 33,4 a $40,5 \%$. Em outro estudo, também conduzido no Brasil, Gerdes et al. (2006) relataram concentrações de PB e de FDN (\% da MS) variando, respectivamente, de 13,07 a $15,35 \%$ e de 63,76 a $66,66 \%$ em três cultivares de triticale colhidas na fase de grãos leitosos. Uma possível explicação para os altos valores de FDN encontrados nesse trabalho, variando entre 71,0 e $81,1 \%$, pode ser redução na presença ou no enchimento dos grãos, parâmetro não avaliado nesse trabalho. Quanto maior a presença de grãos ou quanto mais cheios os grãos, maior a participação de amido na MS. Em trabalhos realizados em outros países, concentrações variando de 30,6 a $37,1 \%$ de MS; de 6,01 a $7,89 \%$ de PB; de 30,4 a 35,8\% de FDA e de 51,6 a $58,3 \%$ de FDN foram apresentados para forragem de diferentes cultivares de triticale, cortadas no estádio de grãos farináceos macios (Juskiw et al., 2000). Estudando diversos aspectos relacionados à fertilização da cultivar de triticalePresto, colhido no estádio de botão floral, Harmoney \& Thompson (2005) relataram concentrações (\% da MS) de PB, FDN e FDA, respectivamente, nas faixas de 5,8 a $13,8 \%$; de 61,5 a $64,5 \%$ e de 38,1 a $41,3 \%$.

Na Tabela 2, são apresentados os parâmetros de degradação ruminal in situ da MS da forragem verde em função da idade de corte do triticale.

O modelo utilizado por Sampaio et al. (1995) que identifica, de modo explicito, dois dos principais elementos de qualificação de forrageiras (taxa e potencial de degradação, respectivamente, "A" e "c"), ajustou-se de modo satisfatório aos dados de degradação da MS dos materiais avaliados. Os coeficientes de determinação $\left(\mathrm{R}^{2}\right)$ obtidos para as curvas de degradabilidade da MS, superiores a $95 \%$, parcialmente, atestaram a adequação desse modelo para caracterização do fenômeno de degradação ruminal das forragens de planta inteira de triticale. 
Tabela 1 - Composição química média da forragem verde picada de triticale em função da idade de corte ${ }^{1,2}$.

\begin{tabular}{ccccc}
\hline Idade de corte (dias) & MS & PB & FDN & FDA \\
\cline { 2 - 4 } & $(\%)$ & $-17,9 \mathrm{~A}$ & $71,0 \mathrm{~A}$ & $38,8 \mathrm{~A}$ \\
73 & $15,2 \mathrm{E}$ & $14,4 \mathrm{~B}$ & $77,3 \mathrm{~A}$ & $43,0 \mathrm{~A}$ \\
80 & $17,3 \mathrm{E}$ & $12,9 \mathrm{BC}$ & $81,1 \mathrm{~A}$ & $44,9 \mathrm{~A}$ \\
94 & $25,9 \mathrm{C}$ & $11,9 \mathrm{C}$ & $76,2 \mathrm{~A}$ & $42,6 \mathrm{~A}$ \\
101 & $21,0 \mathrm{D}$ & $11,4 \mathrm{C}$ & $75,6 \mathrm{~A}$ & $39,9 \mathrm{~A}$ \\
108 & $32,2 \mathrm{~B}$ & $9,7 \mathrm{D}$ & $80,5 \mathrm{~A}$ & $39,1 \mathrm{~A}$ \\
\hline
\end{tabular}

${ }^{1} \mathrm{MS}=$ matéria seca; $\mathrm{PB}=$ proteína bruta; FDN = fibra em detergente neutro; FDA = fibra em detergente ácido.

${ }^{2}$ Médias seguidas por letras iguais na mesma coluna são semelhantes pelo teste SNK $(\mathrm{P}>0,05)$.

Tabela 2 - Parâmetros de degradação ruminal in situ da matéria seca da forragem verde picada do triticale em função da idade de corte ${ }^{1}$

\begin{tabular}{cccccccccc}
\hline $\begin{array}{c}\text { Idade de corte } \\
(\text { dias })\end{array}$ & $\begin{array}{c}\mathrm{A} \\
(\%)\end{array}$ & $\begin{array}{c}\mathrm{B} \\
(\%)\end{array}$ & $\begin{array}{c}\mathrm{c} \\
(\% / \mathrm{h})\end{array}$ & $\begin{array}{c}\mathrm{R}^{2} \\
(\%)\end{array}$ & $\begin{array}{c}\mathrm{S} \\
(\%)\end{array}$ & $\begin{array}{c}\text { LAG } \\
(\mathrm{h})\end{array}$ & DE2 (\%) & DE5 $(\%)$ & $\begin{array}{c}\text { DE8 } \\
(\%)\end{array}$ \\
\hline 73 & 89,5 & 82,1 & 3,8 & 0,97 & 21,4 & 4,9 & 66,2 & 51,0 & 43,5 \\
80 & 80,1 & 69,3 & 3,3 & 0,96 & 22,2 & 5,4 & 58,3 & 45,2 & 39,1 \\
87 & 81,4 & 69,4 & 2,8 & 0,95 & 20,3 & 4,6 & 55,7 & 42,0 & 35,9 \\
94 & 75,2 & 60,1 & 3,0 & 0,96 & 23,3 & 4,9 & 54,5 & 42,9 & 37,6 \\
101 & 76,2 & 59,3 & 2,9 & 0,98 & 23,8 & 4,3 & 54,7 & 42,9 & 37,7 \\
108 & 74,6 & 56,0 & 3,3 & 0,96 & 22,6 & 2,3 & 54,8 & 43,2 & 37,7 \\
\hline
\end{tabular}

${ }^{1} \mathrm{~A}=$ fração potencialmente degradável; $\mathrm{B}$ = fração potencialmente degradável sob ação da microbiota, se não houvesse tempo de colonização (LAG); c = taxa constante de degradação da fração potencialmente degradável por ação da microbiota; $\mathrm{R}^{2}=$ coeficiente de determinação do ajuste do modelo utilizado por Sampaio et al. (1995) aos dados de degradação parcial; $S=$ fração solúvel + partículas com tamanho reduzido que atravessam os poros do náilon; DE2, DE5 e DE8 = respectivamente, degradabilidades efetivas calculadas, considerando taxas de passagem ruminal de $2 ; 5$ e $8 \% / \mathrm{h}$.

Os valores estimados para a taxa de degradação ("c") e para a fração potencialmente degradável ("A") na forragem obtida das plantas com 73 dias de crescimento $(3,8 \% / \mathrm{h}$ e $89,5 \%$,respectivamente) foram superiores àqueles observados nas outras idades de corte. Esse resultadoapresenta-se coerente, uma vez que na forragem obtida aos 73 dias de crescimento do triticale, foram observadas a maior concentração de PB e uma tendência, embora não significativa, para menores teores de FDA e FDN, caracterizando boa qualidade nutricional. Embora apresente melhor perfil nutritivo, o triticale cortado aos 73 dias deve, à princípio, ser utilizado apenas para fornecimento direto no cocho, já que seu baixo teor de MS (15,2\%) inviabiliza a ensilagem desse material (Tomich et al., 2003). Para usá-lo como silagem faz-se necessária pré-secagem visando a reduzir sua umidade.

O maior valor $(23,8 \%)$ para a fração solúvel ("S") foi observado na forragem verde obtida da planta com 101 dias de crescimento, sendo que, nessa idade de corte, foi obtido teor de MS $(32,2 \%)$ próximo daquele recomendado para ensilagem (Produção..., 1997). Essa fração pode estar relacionada à presença de carboidratos solúveis característicos das reservas energéticas das gramíneas (Banys et al., 2001). No entanto, de modo geral, as frações solúveis foram semelhantes entre as forragens verdes nas seis idades de corte, variando de 20,3 a 23,8\%. As frações potencialmente degradáveis ("B") foram superiores para as idades de corte de 73, 80 e 87 dias (Tabela 2) e, talvez, parcialmente expliquem a extensão das degradabilidades potenciais ("A") observadas nas forragens obtidas nestas idades de corte $(89,5 ; 80,1 ; 81,4 \%$, respectivamente). As degradabilidades potenciais ("A”), observadas nas forragens obtidas do triticale cortado aos 94, 101 e 108 dias de crescimento, foram semelhantes entre si, variando de 74,6 a $76,2 \%$ (Tabela 2).

Trabalhando no município de Rio Pomba (MG), com triticale cortado aos 83, 90, 97, 104, 111 e 118 dias de 
crescimento, Lopes et al. (2008) relataram para MS da forragem de triticale, degradabilidade potencial (A) variando de 82,2 a 91,7\%, valores estes, de modo geral, superiores aos observados no presente trabalho. Esses autores ainda relataram taxa de degradação (c), variando de 1,95 a 3,28\%/h; fração solúvel (S) de 19,5 a 27,6\%;; e degradabilidade efetiva sob taxa de passagem ruminal de $5 \% /$ h de 40,5 a 52,8\%. Nas idades de corte de 80 a 108 dias avaliadas no presente trabalho, pode-se considerar que as faixas de variação destes parâmetros de degradação ruminal in situ estão, de modo geral, de acordo com as relatadas por Lopes et al. (2008).

Nas Tabelas 3 e 4, têm-se, respectivamente, os dados referentes à composição química (MS, PB, FDN, FDA) e aos parâmetros de fermentação das silagens de triticale em função da idade de corte da planta. Houve problemas relacionados à conservação da massa ensilada da forragem cortada aos 108 dias de crescimento e, por este motivo, as silagens do triticale nesta idade de corte foram descartadas.

Houve incremento $(\mathrm{P}<0,0001)$ de 0,46 e decréscimo $(\mathrm{P}<0,0512)$ de 0,09 unidades percentuais, respectivamente, nos teores de MS e de PB da silagem, para cada dia adicional na idade de corte das plantas (X) $(\mathrm{MS} \%=-$
$19,790571+0,464357 \mathrm{X} ; \mathrm{r}^{2}=0,56$ e $\% \mathrm{~PB}=20,679179-$ $\left.0,086393 X ; r^{2}=0,15\right)$.

Assim como para as forragens verdes (Tab. 1), não houve diferença $(\mathrm{P}>0,05)$ nas concentrações de FDN das silagens de triticale em função da idade de corte (Tab. 3). Convém ressaltar que as concentrações de FDN observadas nas silagens foram, de modo geral, inferiores àquelas determinadas na forragem verde (respectivamente, 62,79 e 76,95\%; Tab. 1 e 3), o que pode ser considerado atípico, não tendo sido encontrada nenhuma explicação biológica que justifique tal comportamento. Ademais, tanto para a análise do teor de FDN da forragem verde, quanto da silagem de triticale, utilizou-se o mesmo procedimento laboratorial.

Na concentração de FDA na silagem, foi observado decréscimo linear $(\mathrm{P}<0,0207)$ de 0,15 unidades percentuais para cada dia adicional na idade de corte $(\mathrm{X})$ do triticale $\left(F D A \%=54,608000-0,150500 X ; r^{2}=0,22\right)$, sendo o valor médio observado semelhante àquele obtido para as forragens verdes (respectivamente, de 41,5 e 41,4\%; Tab. 1 e 3). No entanto, para as forragens verdes foi observado comportamento quadrático em relação à idade de corte. Avaliando o efeito do estádio de desenvolvimento das plantas ( 89 a 122 dias pós-semeadura) de três cultivares de

Tabela 3 - Composição química da silagem de triticale em função da idade de corte $^{1,2}$.

\begin{tabular}{ccccc}
\hline Idade de corte (dias) & MS & PB & FDN & FDA \\
\cline { 3 - 4 } & $(\%)$ & & $(\%$ da MS & \\
\hline 73 & $13,5 \mathrm{D}$ & $13,7 \mathrm{~A}$ & $62,8 \mathrm{~A}$ & $42,7 \mathrm{~A}$ \\
80 & $17,3 \mathrm{CD}$ & $14,2 \mathrm{~A}$ & $65,7 \mathrm{~A}$ & $42,7 \mathrm{~A}$ \\
87 & $24,7 \mathrm{~B}$ & $13,7 \mathrm{~A}$ & $62,1 \mathrm{~A}$ & $42,2 \mathrm{~A}$ \\
94 & $18,4 \mathrm{C}$ & $12,8 \mathrm{~A}$ & $62,0 \mathrm{~A}$ & $42,1 \mathrm{~A}$ \\
101 & $29,2 \mathrm{~A}$ & $11,4 \mathrm{~A}$ & $61,3 \mathrm{~A}$ & $37,8 \mathrm{~A}$ \\
\hline
\end{tabular}

${ }^{1} \mathrm{MS}=$ matéria seca; $\mathrm{PB}=$ proteína bruta; FDN = fibra em detergente neutro; FDA = fibra em detergente ácido.

${ }^{2}$ Médias seguidas por letras iguais na mesma coluna são semelhantes pelo teste SNK $(\mathrm{P}>0,05)$.

Tabela 4 - Parâmetros de fermentação da silagem de triticale em função da idade de corte ${ }^{1,2}$.

\begin{tabular}{|c|c|c|c|c|c|c|}
\hline \multirow{2}{*}{ Idade de corte (dias) } & \multirow{2}{*}{$\mathrm{pH}$} & \multirow{2}{*}{$\mathrm{NH}_{3} / \mathrm{NT}(\%)$} & Ácido acético & Ácido propiônico & Ácido butírico & Ácido láctico \\
\hline & & & \multicolumn{4}{|c|}{ (\% da MS) } \\
\hline 73 & $5,5 \mathrm{~B}$ & $17,4 \mathrm{~A}$ & $7,05 \mathrm{C}$ & $0,00 \mathrm{~A}$ & $0,30 \mathrm{~A}$ & $0,97 \mathrm{C}$ \\
\hline 80 & $4,5 \mathrm{~A}$ & $17,6 \mathrm{~A}$ & $5,08 \mathrm{BC}$ & $0,10 \mathrm{~A}$ & $0,45 \mathrm{~A}$ & $4,98 \mathrm{~B}$ \\
\hline 87 & $4,0 \mathrm{~A}$ & $8,9 \mathrm{~A}$ & $2,18 \mathrm{~A}$ & $0,88 \mathrm{~A}$ & $0,08 \mathrm{~A}$ & $6,50 \mathrm{~B}$ \\
\hline 94 & $3,7 \mathrm{~A}$ & $11,4 \mathrm{~A}$ & $3,60 \mathrm{AB}$ & $0,63 \mathrm{~A}$ & $0,08 \mathrm{~A}$ & $12,05 \mathrm{~A}$ \\
\hline 101 & $4,3 \mathrm{~A}$ & $13,8 \mathrm{~A}$ & $1,93 \mathrm{~A}$ & $0,20 \mathrm{~A}$ & $0,13 \mathrm{~A}$ & $6,90 \mathrm{~B}$ \\
\hline
\end{tabular}

${ }^{1} \mathrm{MS}=$ matéria seca; $\mathrm{NH}_{3} / \mathrm{NT}=$ nitrogênio amoniacal como porcentagem do $\mathrm{N}$ total.

${ }^{2}$ Valores seguidos por letras iguais na mesma coluna indicam médias semelhantes pelo teste $\mathrm{SNK}(\mathrm{P}>0,05)$. 
triticale no período de inverno em Jaboticabal (SP), Jobim et al. (1996) relataram teores de MS, PB, FDN e FDA na silagem variando, respectivamente, de 28,2 a $47,2 \%$; de 7,2 a $10,9 \%$; de 55,1 a $64,8 \%$; e de 33,4 a $40,5 \%$. Segundo esses autores, houve incremento no teor de MS e decréscimo nas concentrações de PB, FDN e FDA nas silagens obtidas na faixa de idade de crescimento avaliada. Em trabalho conduzido nos EUA, Prostko et al. (2006) relataram concentrações (\% da MS) de PB, FDN e FDA, variando, respectivamente, de 6,6 a $7,4 \%$; de 57,9 a $66,4 \%$ e de 32,0 a $37,1 \%$ para quatro cultivares de triticale colhidas no estádio de grãos farináceos macios.

Quanto à concentração do $\mathrm{pH}$ nas silagens, houve comportamento quadrático $(\mathrm{P}<0,005)$ com a idade de corte do triticale $(\mathrm{X})\left(\mathrm{pH}=44,998109-0,901032 \mathrm{X}+0,004927 \mathrm{X}^{2} ; \mathrm{R}^{2}=\right.$ $0,51)$. Os valores de $\mathrm{pH}$ obtidos nas silagens das plantas com 80 a 101 dias de crescimento variaram entre 3,7 e 4,5, foram semelhantes entre si $(\mathrm{P}>0,05)$ e inferiores ao observado na silagem de triticale cortado aos 73 dias $(5,5)$, conforme a Tabela 4. Não foi constatada diferença $(\mathrm{P}>0,05)$ nas concentrações de $\mathrm{NH}_{3} / \mathrm{NT}$ das silagens de triticale, em função da idade de corte, com o valor médio de 13,40\% (Tabela 4).

Para as concentrações de ácido acético e propiônico na silagem, foram observados decréscimos $(\mathrm{P}<0,01)$, respectivamente, de 0,17 e 0,03 unidades percentuais para cada dia adicional na idade de corte $(\mathrm{X})$ do triticale (\%Ác.acético = 18,537500-0,167500X; $\mathrm{r}^{2}=0,51 ;$ e \%Ác. Propiônico $\left.=3,036141-0,031104 X ; r^{2}=0,33\right)$. Na silagem produzida a partir das plantas cortadas aos 73 dias, foi observada concentração de ácido acético de 7,05\% da MS, valor este superior $(\mathrm{P}<0,05)$ aos obtidos nas silagens de triticale cortado aos 87 a 101 dias de crescimento $(1,93$ a $3,60 \%$ da MS). Não foi observada diferença $(\mathrm{P}>0,05)$ nas concentrações dos ácidos propiônico e butírico das silagens de triticale em função da idade de corte, sendo os valores médios observados, respectivamente, de 0,39 e $0,20 \%$ da MS (Tabela 4). Na silagem produzida a partir das plantas cortadas aos 73 dias foi registrada concentração de ácido lático de $0,97 \%$ da $\mathrm{MS}$, valor este inferior $(\mathrm{P}<0,05)$ aos registrados para as silagens de triticale cortado aos 80,87 e 101 dias de crescimento, respectivamente, de 4,98; 6,50 e $6,90 \%$ da MS. A maior $(\mathrm{P}<0,05)$ concentração de ácido lático (12,05\% da MS) foi observada na silagem produzida a partir das plantas cortadas aos 94 dias de crescimento.

Avaliando o efeito do estádio de desenvolvimento das plantas (89 a 122 dias pós-semeadura) de três cultivares de triticale no período de inverno (Jaboticabal, SP) sobre a qualidade da silagem produzida, Jobim et al. (1996) relataram valores de $\mathrm{pH}$ e concentrações de $\mathrm{NH}_{3} / \mathrm{NT}$ semelhantes às obtidas no presente estudo, variando, respectivamente, de 3,84 a 4,54 e de 8,63 a $25,74 \%$ do $\mathrm{N}$ total.
Calabrò et al. (2005) relataram para silagem de triticale produzida a partir de plantas colhidas quando o grão encontrava-se entre os estádios leitoso a farináceo, valor de $\mathrm{pH}$ de 4,42 e concentrações de $\mathrm{MS}$, de $\mathrm{NH}_{3} / \mathrm{NT}$, e dos ácidos láctico, acético e butírico, respectivamente, de 35,6\%, de 7,57\% do $\mathrm{N}$ total, e de 3,93, 1,65, e $0,28 \%$ da MS. Tais valores estão próximos dos obtidos no presente trabalho.

Tomich et al. (2003) propuseram classificação de qualidade de silagens com base em sistema de pontuação de acordo com os valores de $\mathrm{pH}$ e as concentrações de MS (\%), dos ácidos acético, butírico e láctico (\% da MS) e da concentração de $\mathrm{NH}_{3} / \mathrm{NT}$. Adotando esse método de avaliação, as silagens de triticale obtidas aos 87 e 94 dias de crescimento das plantas alcançaram pontuação de 95 e 90, respectivamente, sendo consideradas de excelente qualidade. Na idade de corte de 101 dias, a silagem foi classificada como de boa qualidade, alcançando 70 pontos e aquelas obtidas das plantas cortadas aos 80 e 73 dias de crescimento foram classificadas como de ruim e péssima qualidade, respectivamente.

Considerando a idade de corte entre 87 e 101 dias, cujas silagens foram consideradas como de excelente e boa qualidade pela classificação proposta por Tomich et al. (2003) observou-se que os níveis de FDN na forragem, variaram entre 75,6 e $81,1 \%$, e, na silagem, entre 61,3 e $62,1 \%$. Essa diminuição é interessante uma vez que aumenta o potencial de consumo pelos animais. Os demais parâmetros bromatológicos apresentaram as variações normais causadas pelo processo fermentativo da ensilagem, evidenciando a viabilidade de utilização do triticale para essa finalidade.

Embora a semeadura do triticale, nesse trabalho, tenha sido feita no início de julho, a época ideal para a Região Sudeste é no início de março (Felício et al., 1999). Semeando nessa época do ano, a ensilagem pode ser realizada na última quinzena de maio e os silos podem ser abertos 30 dias após.

\section{CONCLUSÃO}

O corte do triticale irrigado por aspersão, na Zona da Mata de Minas Gerais, deve ser feito aos 73 dias quando o objetivo for o fornecimento no cocho ou pastejo direto, e entre 83 e 101 dias para conservação na forma de silagem.

\section{REFERÊNCIAS BIBLIOGRÁFICAS}

BANYS, V.L.; PAIVA, P.C.A.; NEIVA, J.N.; SOARES, L.; PINHO, R.G. Degradabilidade in situ de quatro gramíneas tropicais em bovinos. In: REUNIÃO ANUAL DA SOCIEDADE BRASILEIRA DE ZOOTECNIA, 38., 2001, Piracicaba. Anais... Piracicaba: SBZ, 2001. CD-ROM. 
BAIER, A.C. Triticale. In: BAIER, A.C.; AUDE, M.I.S.; FLOSS, E.L. As lavouras de inverno-1. São Paulo: Globo, 1989. p.76-106.

BAIER, A.C.; NEDEL, J.L. Potencial do triticale no Brasil. Pesquisa Agropecuária Brasileira, Brasília, v.20, n.1, p.57-67, jan. 1985.

BORTOLINI, P.C.; SANDINI, I.; CARVALHO, P.C.S.; MORAES, A. Cereais de inverno submetidos ao corte no sistema de duplo propósito. Revista Brasileira de Zootecnia, Viçosa, v.33, n.1, p.45-50, 2004.

CALABRÒ, S.; CUTRIGNELLI, M.I.; PICCOLO, G.; BOVERA, F.; ZICARELLI, F.; GAZANEO, M.P.; INFASCELLI, F. In vitro fermentation kinectics of fresh and dried silage. Animal Feed and Science Technology, Amsterdã, v.123/124, p.129-137, 2005.

CARVALHO, F.I.F.; FEDERIZI, L.C.; NADARI, R.O.; SHEEREN, P.L.; SEVERO, M.J. Trigo, triticale, aveia e cevada na depressão central do RS. Revista Lavoura Arrozeira, Porto Alegre, n.33, p.34-39, abr. 1980.

COLLAR, C.; WRIGHT, S.; ROBINSON, P.; PUTNAM, D. Effect of harvest timing on yield and quality of small grain forage. In: NATIONAL ALFALFA SYMPOSIUM, 2004, San Diego. Proceedings... San Diego: University of California, 2004. Disponível em: ‘http://alfalfa.ucdavis.edu/symposium/ 2004/proceedings/CarolCollarGRAINpaperFINĀLE.pdfy. Acesso em: 17 nov. 2006.

FELICIO, J.C.; CAMARGO, C.E.O.; CASTRO, J.L.; CAMARGO, J.B.P. Épocas de semeadura de triticale em Capão Bonito, SP. Pesquisa Agropecuária Brasileira, Brasília, v.34, n.12, p.2193-2202, 1999.

FEROLLA, F.S.; VASQUEZ, H.M.; SILVA, J.F.C.; VIANA, A.D.; DOMINGUES, F.N.; AGUIAR, R.S. Produção de matéria seca, composição da massa de forragem e relação lâmina foliar/caule + bainha de aveia-preta e triticale nos sistemas de corte e pastejo. Revista Brasileira de Zootecnia, Viçosa, v.36, n.5, p 1512-1517, 2007.

GERDES, L.; IAPICHINI, J.E.C.B.; FERRARI JÚNIOR, E.; BIANCHINI, D.; RODRIGUES, C.F.C.; LIMA, J.A.; POSSENTI, R.A.; CASTRO, J.L. Avaliação de variedades de cereais de inverno na alimentação animal. Campinas: Agência Paulista de Tecnologia dos Agronegócios, 2006. Disponível em: <http://
IWww.aptaregional.sp.gov.br/artigo.php? id artigo=344خ' Acesso em: 14 nov. 2006.

HARMONEY, K.R.; THOMPSON, C.A. Fertilizer rate and placement alters triticale forage yield and quality. Saint Paul: Plant Management Network, 2005. Disponível em: $<$ http:// Www.plantmanagementnetwork.org/pub/fg/research/ 2005 /fertilizery $>$. Acesso em: 17 nov. 2006.

JAYME, C. G.; MOLINA, L. R.; GONÇALVES, L. C.; JAYME, D. G.; PIRES, D. A. de A.; BORGES, I. Determinação do momento de colheita da Brachiaria brizantha (Hochest.) Stapf. cv. Marandu para produção de silagem. Ciência \& Agrotecnologia, Lavras, v.33, n.2, p. 586-591,mar./abr., 2009.

JOBIM, C.C.; EMILE, J.; LILA, M.; SARAULT, F. Composição química e digestibilidade in vitro da forragem de cereais de inverno em diferentes estádios de desenvolvimento. In: REUNIÃO ANUAL DA SOCIEDADE BRASILEIRA DE ZOOTECNIA, 1999, Porto Alegre. Anais... Porto Alegre: Sociedade Brasileira de Zootecnia, 1999. v.1, p.34-36.

JOBIM, C.C.; REIS, R.A.; RODRIGUES, L.R.A. Avaliação do triticale ("X Triticosecale" Wittimacck) para silagem.

Revista Brasileira de Zootecnia, Viçosa, v.25, n.3, p.405413, 1996.

JUSKIW, P.E.; HELM, J.H.; SALMON, D.F. Forage yield and quality for monocrops and mixtures of small grain cereals. Crop Science, Madison, v.40, p.138-147, 2000.

LOPES, F.C.F.; OLIVEIRA, J.S.; LANES, E.C.M. Valor nutricional do triticale (X Triticosecale Wittimack) para uso como silagem na Zona da Mata de Minas Gerais. Arquivo Brasileiro de Medicina Veterinária e Zootecnia, Belo Horizonte, v.60, p.1484-1492, 2008.

MOREIRA, A. L.; REIS, R. A.; RUGGIERI, A. C.; SARAN JUNIOR, A. J. Avaliação de forrageiras de inverno irrigadas sob pastejo. Ciência \& Agrotecnologia, Lavras, v.31, n.6, p.1838-1844, Nov./dez., 2007.

PEREZ GOMAR, E.; BEMAHAJA, M. Caracterización y perspectivas de las rotaciones en los suelos arenosos del noreste del Uruguay. Investigaciones Agronómicas, Montevideo, v.2, p.205-214, 1992. 
PRODUÇÃO de silagem: como reduzir perdas e garantir boa qualidade. Três Corações: BIOTECNAL, [1997]. 45p.

PROSTKO, E.P.; MUIR, J.P.; WORRALL, W.D.; STOKES, S.R. Forage and silage performance of wheat and triticale varieties in Central Texas. Stephenville: Texas A\&M System Research and Extension Center, 2006. Disponível em: 〈http://foragesoftexas tamu.edü ipdf/frt198.pdf >. Acesso em: 16 nov. 2006.

RUIZ, M.A.; GOLBERG, A.D.; MARTINEZ, O. Forage and seed production of tricepiro, triticale and trigopiro under water stress. Revista Argentina de Producción Animal, Buenos Aires, v.27, n.1, p.188-189, 2007.

SAMPAIO, I.B.M.; PIKE, D.J.; OWEN, E. Optimal design for studying dry matter degradation in the rumen.

Arquivo Brasileiro de Medicina Veterinária e

Zootecnia, Belo Horizonte, v.47, p.373-383, 1995.

SAS INSTITUTE. SAS user's guide: statistics. Version 5. Cary, 1985. 956p.

SILVA, D.J.; QUEIROZ, A.C. de. Análise de Alimentos: métodos químicos e biológicos. Viçosa, MG: UFV, 2002. 235p.
TOMICH, T.; PEREIRA, L.G.R.; GONÇALVES, L.C.; TOMICH, R.G.P.; BORGES, I. Características químicas para avaliação do processo fermentativo de silagens: uma proposta para qualificação da fermentação. Corumbá: Embrapa Pantanal, 2003. 20p. (Embrapa Pantanal. Documentos, 57).

TOMICH, T.R.; SAMPAIO, I.B.M. A new strategy for the determination of forage degradability with an in situ technique through the use of one fistulated ruminant. Journal of Agricultural Science, Cambridge, v.142, p.589-593, 2004.

VEASEY, E.A.; GHISI, O.M.A.A.; VALARINI, M.J.; OTSUK, I.P.; CARDELLI, M.A.; SANCHEZ, M.J.F.; BEISMAN, D.A. Early growth and native nodulation of leguminous shrub and tree species in Brazil. Tropical Grasslands, Queensland, v.31, p.40-48, 1977.

ZANOTTO, M.; BRAMMER, S. P.; NASCIMENTO JUNIOR, A. do; SCAGLIUSI, S. M. Viabilidade polínica como seleção assistida no programa de melhoramento genético de triticale. Ciência \& Agrotecnologia, Lavras, v.33, Edição Especial, p.2078-2082, 2009. 